\title{
Tailoring the viscoelastic properties of injectable biocomposites: A spectroscopic assessment of the interactions between organic carriers and bioactive glass particles
}

\author{
I. Gonzalo-Juan ${ }^{\text {a }}$, D. U.Tulyaganov ${ }^{\mathrm{a}, \mathrm{b}, \mathrm{c}}$, C. Balan $^{\mathrm{d}}$, R. Linser ${ }^{\mathrm{e}}$, J.M.F. Ferreira ${ }^{\mathrm{b}}$, R. Riedel $^{\mathrm{a}}$, E. Ionescu ${ }^{\text {a,f }}$ \\ a Technische Universität Darmstadt, FB Material- und Geowissenschaften, Jovanka-Bontschits-Strasse 2, D-64287 Darmstadt, Germany \\ ${ }^{\mathrm{b}}$ University of Aveiro, Department of Materials and Ceramic Engineering, CICECO, Portugal \\ c Turin Polytechnic University in Tashkent, 17, Niyazova (Small ring), 100095, Tashkent, Uzbekistan \\ d Politehnica University Bucharest, REOROM Laboratory, Splaiul Independentei 313, 060042 Bucharest, Romania \\ e Max-Planck Institute for Biophysical Chemistry, Department NMR-Based Structural Biology, 37077 Göttingen, Germany \\ ${ }^{\mathrm{f}}$ Universität zu Köln, Institut für Anorganische Chemie, Greinstrasse 6, D-50939 Köln, Germany
}

\section{A R T I C L E I N F O}

Article history:

Received 16 December 2015

Received in revised form 19 February 2016

Accepted 20 February 2016

Available online 23 February 2016

\section{Keywords:}

Injectable biocomposites

Bioglass

PEG

Glycerol

Pastes

\begin{abstract}
A B S T R A C T
Injectable bioglass (BG) pastes were produced using a melt-quenched glass based on $\mathrm{CaO}-\mathrm{MgO}-\mathrm{SiO}_{2}-\mathrm{Na}_{2} \mathrm{O}-$ $\mathrm{P}_{2} \mathrm{O}_{5}-\mathrm{CaF}_{2}$ and two organic carriers, namely polyethylene glycol (PEG) and glycerol (Gly). The interactions between the organic carriers and the surface of the BG particles were assessed by spectroscopic methods (Fourier Transform Infrared, Raman, as well as 29Si and 13C solid-state NMR spectroscopy) in order to understand their effects on the viscoelastic properties of the biocomposites. While pure physical interactions were detected between PEG and the surface of the BG particles, chemical bonding was observed between glycerol and BG, enhancing the network cross-linking degree. Accordingly, the BG network of Gly-BG pastes was more condensed (higher fraction of Q [3] units detected by Raman spectroscopy) in comparison to that of PEG-BG and bare BG. Such chemical interactions between the organic carrier and BG were shown to negatively affect the viscoelastic behaviour of the resulting pastes. Thus, the PEG-based biocomposite exhibited improved flowability in comparison to its analogous Gly-BG biocomposite.
\end{abstract}

(c) 2016 Elsevier Ltd. All rights reserved.

\section{Introduction}

Biocomposites often consist of a biocompatible polymeric matrix reinforced by an inorganic phase [1-3]. The interactions between the organic and inorganic phases in biocomposites create materials that exhibit synergistically enhanced properties as compared to their individual components. Typically, two classes of organic/inorganic composites (hybrid materials) have been defined: class I hybrids represent composites in which there is a weak interaction between the organic and the inorganic phases, such as van der Waals or hydrogen-bond forces; whereas class II hybrids consist of composites showing covalent or iono-covalent bonds between the organic and inorganic phases [4].

Injectable biocomposite pastes based on bioactive glass (BG) particles dispersed within a biocompatible (and ideally bioresorbable) organic matrix have emerged recently as an important family of filler materials for bone and tooth treatments [5]. In order to achieve an appropriate injectability, the biocomposites should exhibit tailored viscoelastic properties and ideally undergo a rheological transition from a visco-elastic fluid to a elasto-plastic solid behaviour within a certain time. Thus, appropriate visco-elastic properties allow pastes to be easily injected; whereas, their post solidification is of crucial importance to provide mechanical stability in the implanted area. It is anticipated that the composition of the pastes, and the nature of the interactions between their organic and inorganic components might have a significant impact on the rheological properties under shear, and on the structural recovering behaviour under rest conditions.

Interestingly, so far only few investigations have been focused on the effects of the organic-BG interactions on the visco-elastic properties and structural recovery of composites. The influence of the BG particle size on the dynamic rheological changes over time (viscosity, storage and loss moduli) was recently investigated [6-8]. The main efforts aimed at tailoring the compositions and the textural properties of BG-organic carriers in order to improve the biomineralisation kinetics, i.e., the deposition of a surface apatite layer [9-12].

In the present work we report on the preparation of novel injectable biocomposites based on the melt-quenched glass $\mathrm{CaO}-\mathrm{MgO}-\mathrm{SiO}_{2}-$ $\mathrm{Na}_{2} \mathrm{O}-\mathrm{P}_{2} \mathrm{O}_{5}-\mathrm{CaF}_{2}$, which was recently used in clinical studies concerning healing of bone defects $[13,14]$. The specific aim of this study is to 
investigate how the interactions between the organic phase, i.e. glycerol (Gly) or polyethylene glycol (PEG), and the surface of the BG particles affect the rheological properties and the structural recover under small oscillatory deformations.

\section{Materials and methods}

\subsection{Preparation of the biocomposites}

A bioactive glass ( $\mathrm{BG}$ ) with the nominal composition (mol\%) $4.33 \mathrm{Na}_{2} \mathrm{O}-30.30 \mathrm{CaO}-12.99 \mathrm{MgO}-45.45 \mathrm{SiO}_{2}-2.60 \mathrm{P}_{2} \mathrm{O}_{5}-4.33 \mathrm{CaF}_{2}$ was produced from powders of technical grade of silicon oxide (purity 99.5\%) and calcium carbonate (99.5\%) and of reagent grade $4 \mathrm{MgCO}_{3} \cdot \mathrm{Mg}(\mathrm{OH})_{2} \cdot 5 \mathrm{H}_{2} \mathrm{O}, \mathrm{Na}_{2} \mathrm{CO}_{3}, \mathrm{CaF}_{2}$, and $\mathrm{NH}_{4} \mathrm{H}_{2} \mathrm{PO}_{4}$. Thus, glassfrits were prepared by quenching the melt into cold water as described elsewhere [13-15]. The frits were dried and then milled in a high speed porcelain mill to obtain BG powders with mean particle sizes within the range of $11-14 \mu \mathrm{m}$, as determined by light scattering technique, Coulter LS 230, UK, Fraunhofer optical model. Polyethylene glycol 400 (Fluka) or polyol Glycerol (Fluka) were used as organic carriers for the BG particles. The components were premixed in small plastic boxes using a metallic spatula before feeding the mixtures in a laboratory mixer (IKA RW 47 Digital Pilot-Process Mixer, Cole Parmer) at room temperature and $30 \mathrm{rpm}$. Table 1 summarizes the composition of the prepared pastes.

\subsection{Materials characterization}

Scanning electron microscopy (SEM) analysis was performed on a Philips XL30 FEG, Netherlands with an acceleration voltage of 10-15 kV. FTIR spectra were collected with a VARIAN 670IR spectrophotometer using attenuated total reflection (ATR) mode.

All solid-state NMR spectra were recorded using a Bruker Avance spectrometer operating at $400 \mathrm{MHz}$ proton Larmor frequency. Magicangle spinning (MAS) of $11 \mathrm{kHz}$ was pursued using $4 \mathrm{~mm}$ rotors. Acquisition times amounted to $15 \mathrm{~ms}$ upon use of $76 \mathrm{kHz}$ SPINAL-64 decoupling. Recycle delays amounted to $2.5 \mathrm{~s}$ and $15 \mathrm{~s}$ for $13 \mathrm{C}$ and 29Si spectra, respectively. 1H, 13C, and 29Si hard pulses were applied at $76 \mathrm{kHz}(3.3 \mu \mathrm{s}), 42 \mathrm{kHz}(6 \mu \mathrm{s})$, and $50 \mathrm{kHz}(5 \mu \mathrm{s})$. CP conditions included a $90-100 \%$ ramp on $13 \mathrm{C}$ at a $\mathrm{B}_{1}$ field of $37 \mathrm{kHz}$ and $53 \mathrm{kHz}$ on $1 \mathrm{H}$ for a duration of $1 \mathrm{~ms}$. $1 \mathrm{H}$ hard pulses were applied at $76 \mathrm{kHz} \mathrm{B}_{1}$. Temperature was maintained to approximately $10^{\circ} \mathrm{C}$.

The spectra were recorded using total acquisition times of 2 and $8 \mathrm{~h}$ for single-pulse (HPDEC) 29Si experiments (without and with PEG, respectively), 24 and $36 \mathrm{~h}$ for carbon CP spectra (without and with PEG, respectively), and 8 and $24 \mathrm{~h}$ for carbon HPDEC spectra (without and with PEG, respectively).

The rheological properties of the composites were conducted in oscillatory mode, i.e. frequency sweep at a constant strain amplitude of 0.1 [ - ] (TA Instruments AR-G2 rheometer, plate-plate geometry with diameter $25 \mathrm{~mm}$ and gap of $200 \mu \mathrm{m}$ ). The as-prepared pastes were soft enough to be molded and extruded with a syringe.

\section{Results and discussion}

The morphological features of the as-obtained $\mathrm{CaO}-\mathrm{MgO}-\mathrm{SiO}_{2}-$ $\mathrm{B}_{2} \mathrm{O}_{3}-\mathrm{Na}_{2} \mathrm{O}-\mathrm{CaF}_{2}$ glass particles are shown in Fig. 1. The micrographs show that the main fraction consists of particles with sizes around 11-14 $\mu \mathrm{m}$ with conchoidal and subconchoidal fracture surfaces. These features are commonly observed in comminuted glassy materials.

Table 1

Formulation of the investigated pastes (wt.\%).

\begin{tabular}{llll}
\hline Paste & BG & PEG 400 & Glycerol \\
\hline Gly-BG & 72.5 & - & 27.5 \\
PEG-BG & 77.0 & 23.0 & - \\
\hline
\end{tabular}

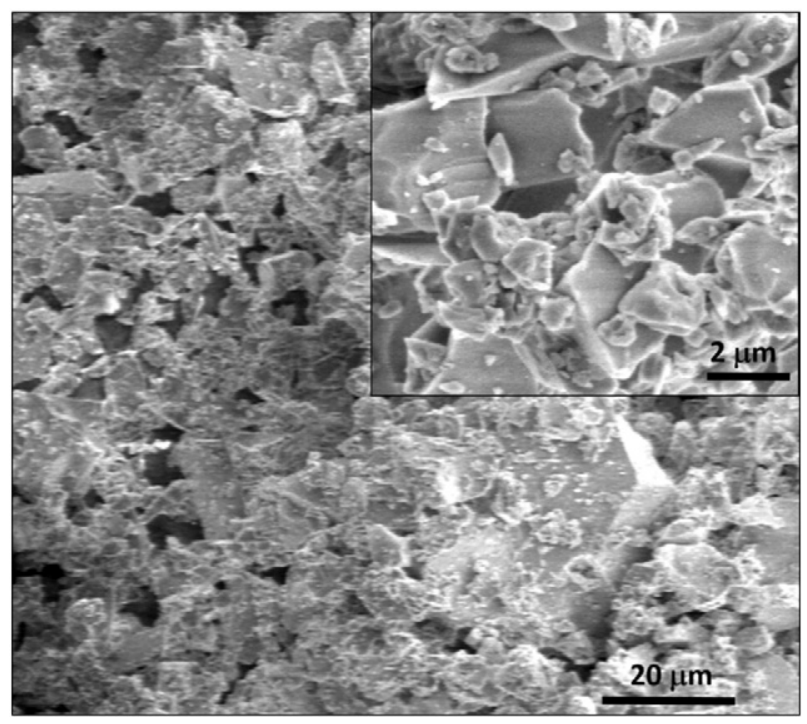

Fig. 1. SEM micrograph of the as-synthesized BG particles.

The structural silicate network features of the as-synthesized BG particles and of the organic-BG composites assessed by Raman and MAS-NMR spectroscopy are displayed in Fig. 2. The 29Si MAS-NMR spectra of the BG particles and the PEG-BG paste are shown in Fig. 2a, red and blue lines, respectively. Both spectra are identical, revealing the dominance of the $\mathrm{Q}[2]$ structural units giving a signal with a chemical shift of $-84 \mathrm{ppm}$. It was not possible to analyze the paste containing glycerol MAS-NMR spectroscopy, as its high liquid content did not allow for spinning the sample. Consequently, this sample was studied only by Raman spectroscopy. The Raman spectrum of the assynthesized BG particles (Fig. 2b, BG) is in good agreement with the NMR results. It shows that the network is mostly dominated by $Q$ [2] units, which exhibit a strong band at $950 \mathrm{~cm}^{-1}$. The presence of the absorption bands corresponding to Q [3] (at $1040 \mathrm{~cm}^{-1}$ ) and Q [1] $\left(882 \mathrm{~cm}^{-1}\right)$ were also evident, although with low intensity [16]. Interestingly, the $\mathrm{Q}$ [2] band at $950 \mathrm{~cm}^{-1}$ disappeared upon mixing the BG powder with glycerol in the Gly-BG biocomposite (Fig. 2b, Gly-BG) and the intensity of the band at $1050 \mathrm{~cm}^{-1}$ assigned to $\mathrm{Q}$ [3] species was significantly enhanced in comparison to that observed for the asprepared BG.

The interactions between the organic carriers and the BG particles in the as-prepared pastes were also assessed by FTIR spectroscopy (Fig. 3). The spectrum of PEG-BG (Fig. 3b) reveals the same spectral features of pure BG and PEG [17].

Pure glycerol exhibits two characteristic peaks at 1112 and $1038 \mathrm{~cm}^{-1}$ (Fig. 3a), which are characteristic of the $\mathrm{C}-\mathrm{OH}$ stretching vibrations (secondary and primary alcohols, respectively) [18]. However, for the as-prepared Gly-BG paste, these absorptions bands were shifted towards lower wavenumbers (i.e., 1104 and $1027 \mathrm{~cm}^{-1}$, respectively, Fig. 3a) and were assigned to C-O-R stretching [19], indicating that glycerol is chemically bonded to the surface of the BG particles. The obtained results are in agreement with the Raman spectroscopy data, confirming that glycerol chemically interacts with the surface of BG particles through $\mathrm{C}-\mathrm{O}-\mathrm{Si}$ bounds. This fact consequently reduces the fraction of the $\mathrm{Q}[2]$ units in the BG and is also likely to alter its demonstrated bioactivity.

Additionally, 13C MAS-NMR spectroscopy using cross-polarization (CP) from 1H (Fig. 4a) and using single-pulse excitation (Fig. 4b) was performed for BG and PEG-BG samples. CP addresses only the rigid components of the sample. Apart from a minimal, unspecific background signal, no rigid carbon spins are expected in either sample. In the presence of PEG, however, some additional contribution from a carbon- and proton-containing subset of temporarily adhered molecules is observed, 

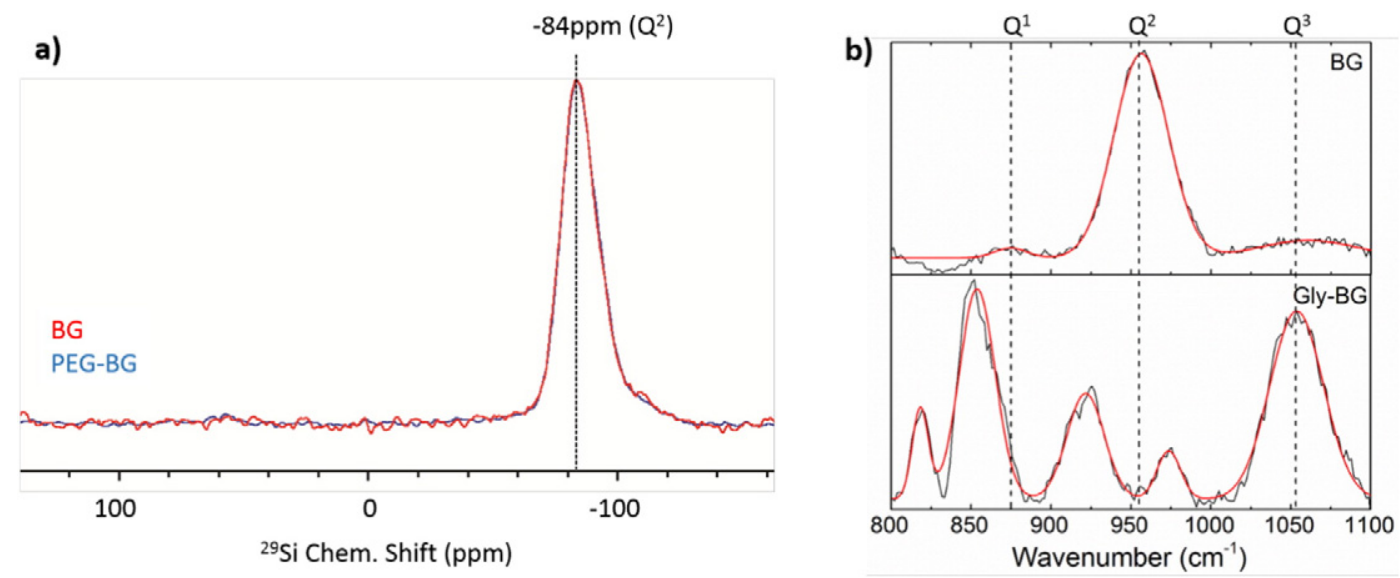

Fig. 2. a) 29Si CP-MAS spectra of BG (red) and PEG-BG (blue), b) Raman spectra of the as-synthesized BG particles (BG) and Gly-BG paste.

as can be seen in the difference spectrum (gray). The additional rigidified-carbon contribution in the $\mathrm{CP}$ spectra has $13 \mathrm{C}$ chemical shifts that match those of PEG, as observed in the single-pulse excitation spectrum of the BG-PEG sample, where both mobile as well as rigid species show up. A small fraction of the PEG (on the order of $1-2 \%$ judged by spectral integrals) seems to just partially and/or temporarily be rigidified by transient physical surface interactions (not chemical interactions) with the BG. The same observation has been made earlier for water molecules temporarily adhering to protein surfaces [20].

Consequently, the BG network of the Gly-BG paste was more condensed (more fraction of $Q$ [3] units detected by Raman spectroscopy) than the network of PEG-BG and bare BG as is illustrated in Fig. 5.

It is important to note that preliminary injectability tests attempted in an earlier study [21] revealed that glycerol lends stiffness to the pastes, but the reason behind this phenomenon was not fully understood. The visco-elastic properties of the pastes, now assessed through oscillatory tests, are shown in Fig. 6. Both Gly-BG and PEG-BG samples disclose qualitatively similar complex viscosity $\eta^{*}(\omega)$ curves with values decreasing by $1-2$ orders of magnitude upon increasing the applied frequency in the range of $\omega \in\left[0.1 \div 10^{2}\right] 1 / \mathrm{s}$. Within this frequency domain, the pastes are predominantly viscous, with $G^{\prime \prime}>G^{\prime}$, i.e. $\tan \delta>1$ (where $G^{\prime}$ is the elastic modulus, $G^{\prime \prime}$ is the viscous modulus and $\left.\tan \delta:=G^{\prime \prime} / G^{\prime}\right)$.

Fig. 6a reveals that the PEG-BG paste is more viscous than the Gly-BG one. This can be understood considering the lower solids content of GlyBG (Table 1). However, the elastic modulus of the PEG-BG sample is almost constant with respect to frequency, suggesting that its network is less sensitive to the applied deformation. On the contrary, the measured elastic modulus of the Gly-BG paste is increasing with frequency. Consequently, its internal network includes a component that is sensitive to the applied deformation. Based on the spectroscopy data reported in Fig. 3, one can conclude that this contribution was brought about by the chemical interactions between the two components of the Gly-BG paste, conferring it more pronounced viscoelastic features. Fig. $6 \mathrm{~b}$ shows that $\tan \delta$ values for the Gly-BG paste are generally larger than for the PEG-BG one, except within the higher frequency range. The
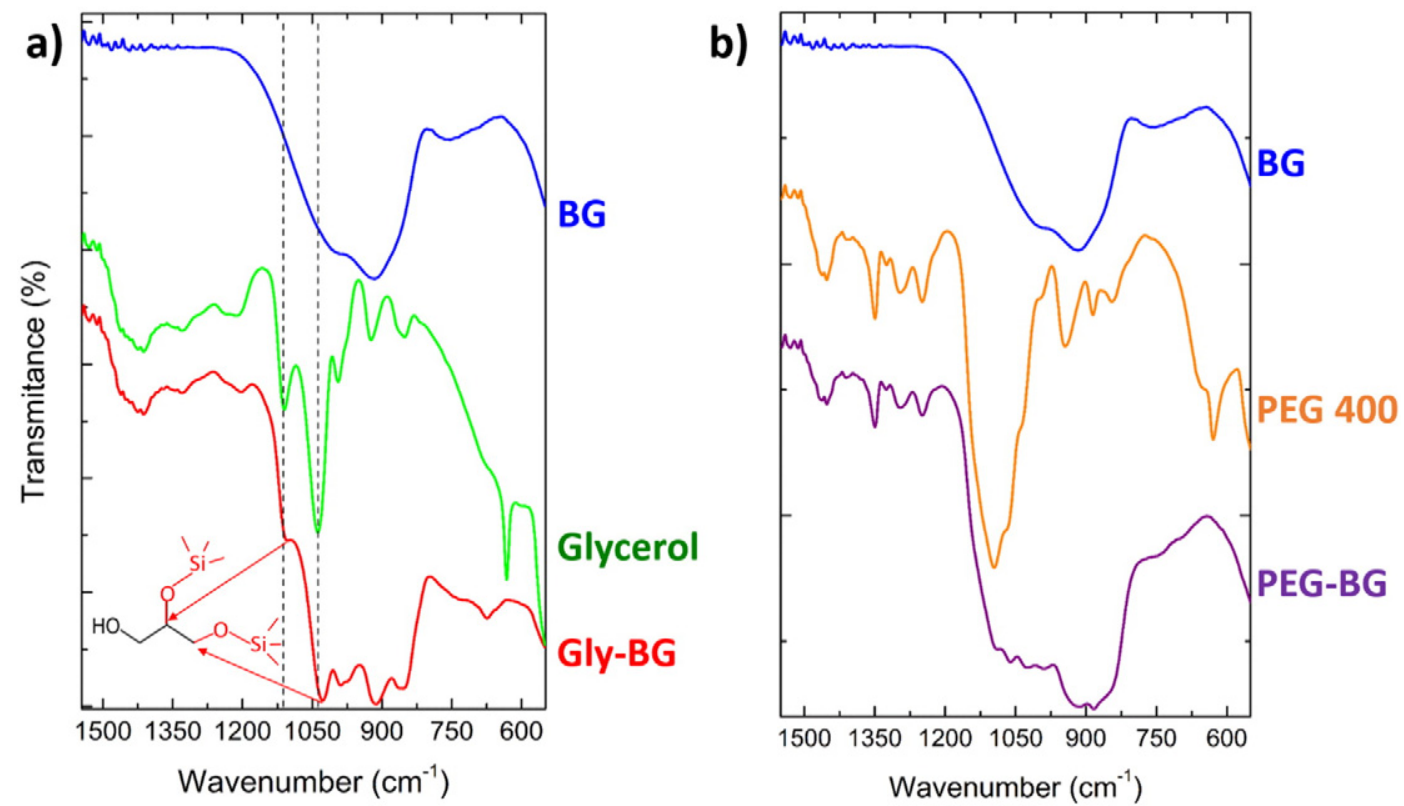

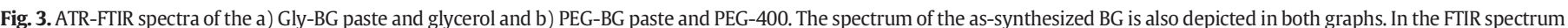

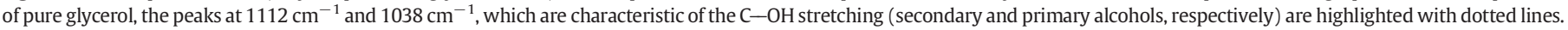

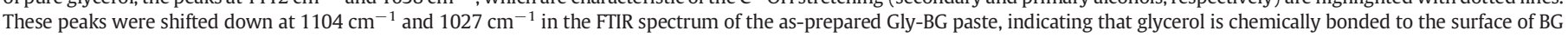
particles forming an ester bound between both the primary and the secondary alcohols of the glycerol and the Si of the BG. 


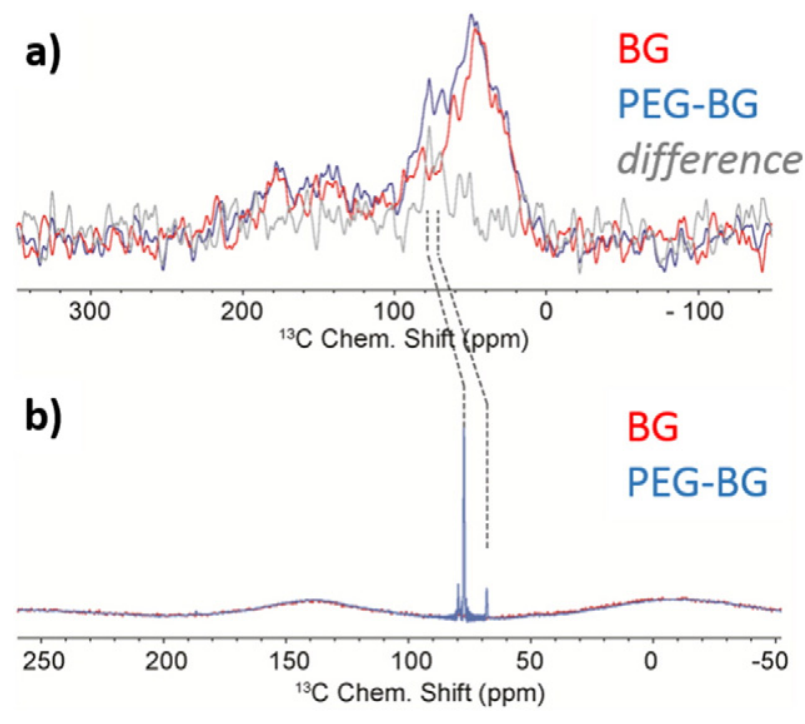

Fig. 4. 13C solid-state NMR spectra of BG (red line) and PEG-BG paste (blue line) obtained using a) cross-polarization ( $\mathrm{CP}$ ) from $1 \mathrm{H}$ and $\mathrm{b}$ ) single-pulse excitation.

positioning of the tan $\delta$ curve of Gly-BG paste within the lower frequency range means that the viscous character predominates over the elastic one, a fact that can be attributed to its lower BG content. But with the continuous increase of deformation frequency, the chemical bonds established between the Gly-BG components of the paste have less time to relax and the elastic component starts playing a major role, explaining why $\tan \delta$ decreases.

Considering that the pastes are concentrated suspensions of BG particles dispersed in a carrying fluid, it is expected that BG particles will interact with each other and with the liquid separating them and occupying the interstitial pores, conferring a certain structure to the systems under rest. This explains why the flow curves reconstructed from oscillatory tests exhibit apparent yield stress values at low shear rate/ frequency (Fig. 7a). The manifestation of yield stress indicates that pastes start to flow at observable shear rates beyond a certain threshold $\left(\sigma_{0}\right)$ of the applied shear stress, being higher for PEG-BG $\left(\sigma_{0}>8 \mathrm{~Pa}\right)$ in comparison to Gly-BG $\left(\sigma_{0}>1 \mathrm{~Pa}\right)$. This significant difference of about eight times in measured yield stress values is again related to the lower BG content (72.5 wt.\%) of the Gly-BG paste in comparison to that of PEG-BG sample (77.0 wt.\%). Fig. 7a also reveals that both pastes exhibit pseudo-plastic behaviours expressed by the faster increasing trends of shear stress with increasing deformation rate at low and medium values. This behaviour is more accentuated in the case of Gly-BG paste. The rheological behaviour is controlled by a number of factors such as particle shape, size, and size distribution, and the specific interactions between the solvent molecules and/or dissolved species and the surface of the particles [21]. A tendency of shear thickening behaviour is observed when agglomeration of particles is induced by shear, denoting poor flow propensity under high shear rates. This means that there is room for further improving the flow behaviour of the pastes by suitably adjusting the experimental parameters that play the key roles in determining their rheological behaviour [22]. The present work demonstrates that the specific interactions between the molecules of the carrying liquids and the surface of BG particles exert a great influence on the maximum achievable solids loading and on flow behaviour of the resulting pastes. The shear stress of the Gly-BG paste involving chemical solid-liquid interactions increased much faster with the deformation rate increasing, even though it contains a lower solids loading. The same solid-liquid interactions help explaining why the shape of extruded Gly-BG paste preserves its shape for a longer time after extrusion in comparison to PEG-BG one as observed in Fig. 7b.

\section{Conclusions}

Hybrid, bio-composite pastes based on bioglass particles dispersed in organic liquid matrices (PEG, or glycerol) were prepared and the interactions between the carrying liquids and the surface of BG particles were assessed by several spectroscopic techniques. The results of FTIR and Raman spectroscopy clearly indicated the occurrence of chemical bonding between the surface of BG particles and Gly. Contrarily, only physical interactions were detected in the case of PEG-BG paste, as revealed by FTIR, 29Si and 13C NMR spectroscopy. Consequently, the maximum achievable solid loading was lower in the case of Gly-BG

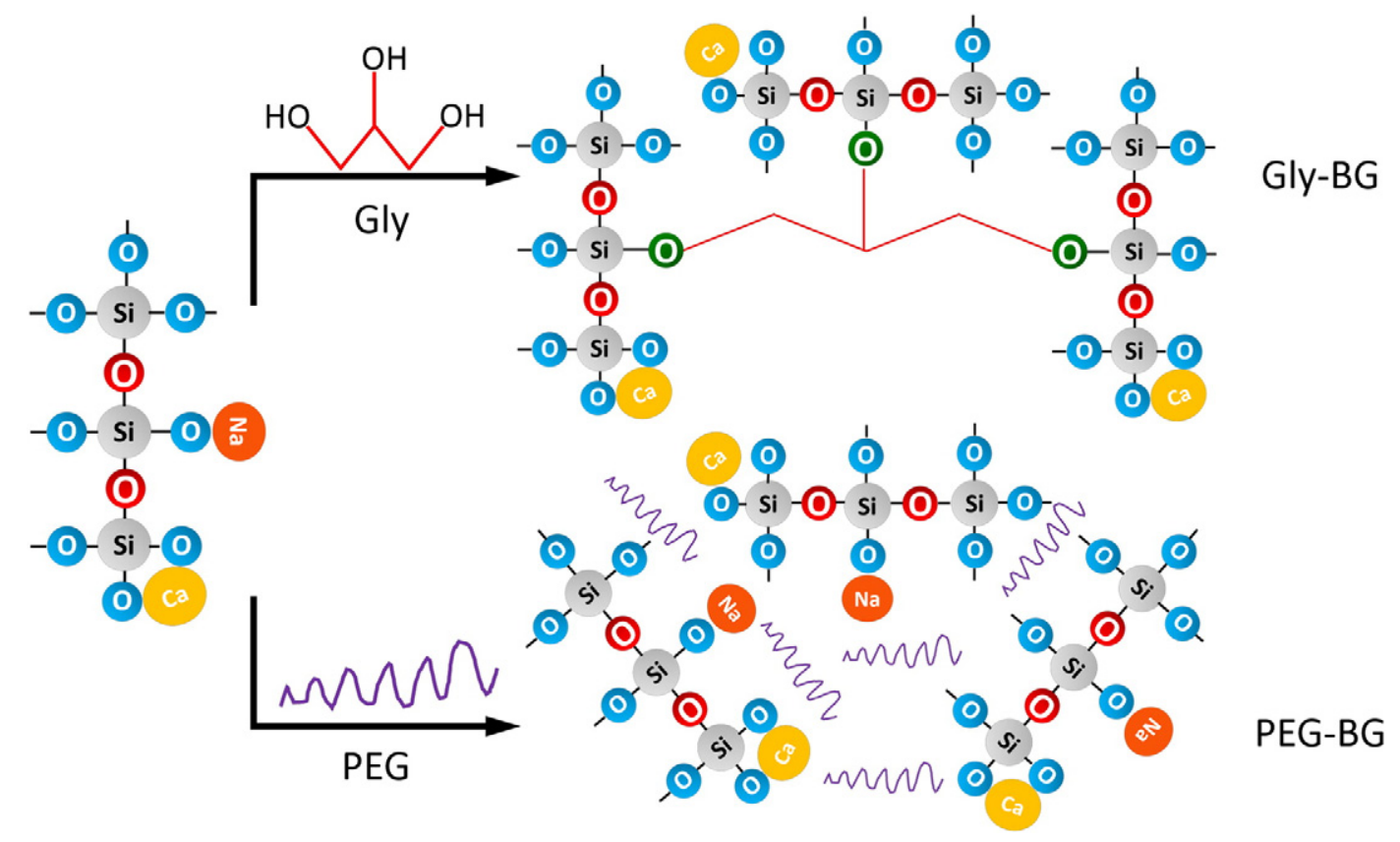

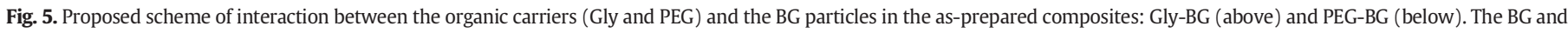

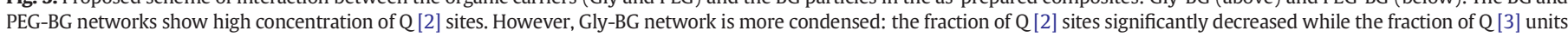
increased due to the covalent interaction between $\mathrm{BG}$ particles and the $-\mathrm{OH}$ groups of Gly. 

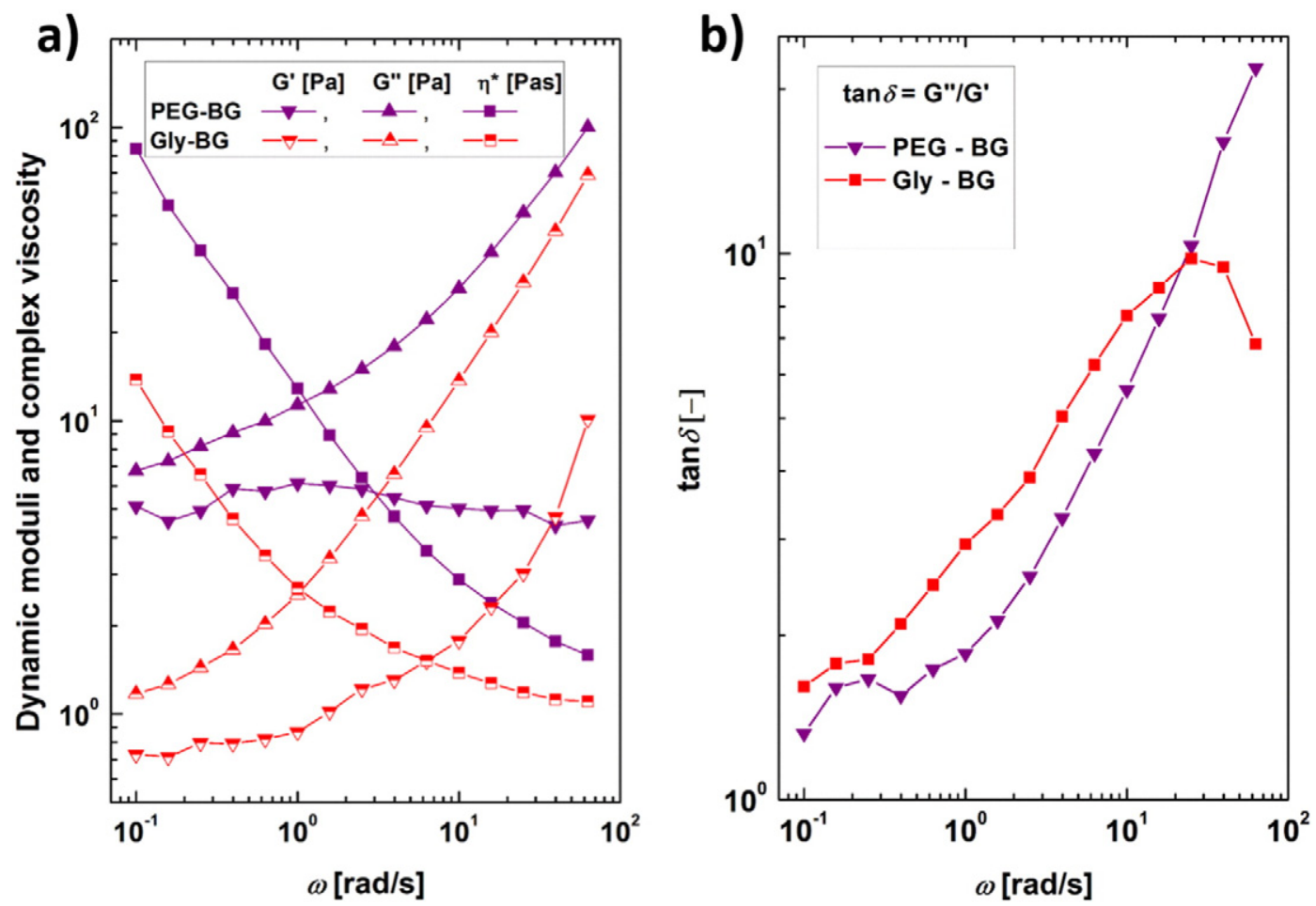

Fig. 6. a) Dynamic moduli and the dynamic viscosity measured in the frequency sweep test and b) tano as function of the angular frequency.

paste and the BG phase exhibits an apparently more condensed network in comparison to PEG-BG.

Rheological investigation of the as-prepared hybrid samples revealed that both pastes exhibit pseudo-plastic behaviours, more accentuated in the case Gly-BG paste due to the chemical nature and extent of the interactions between the BG phase and the organic liquid. Accordingly, the Gly-BG paste preserves its shape longer after extrusion than the PEG-BG paste, which flows more under near rest

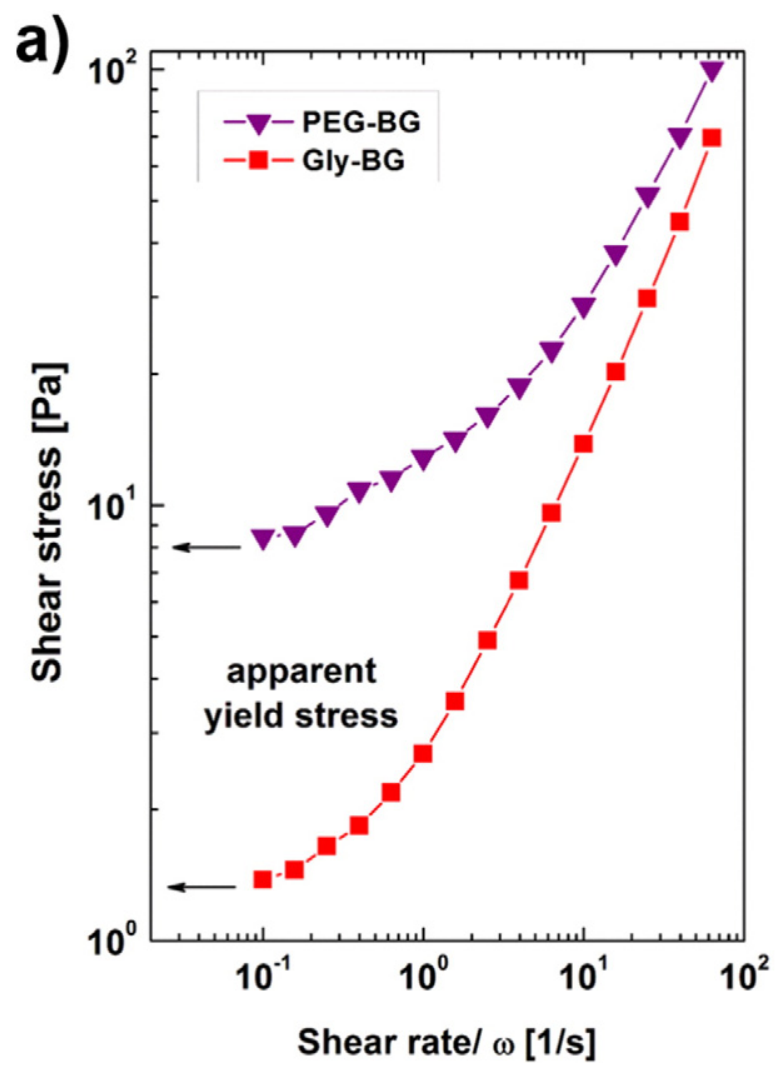

b) Time after extruding
$0 \mathrm{~min}$
$10 \mathrm{~min}$

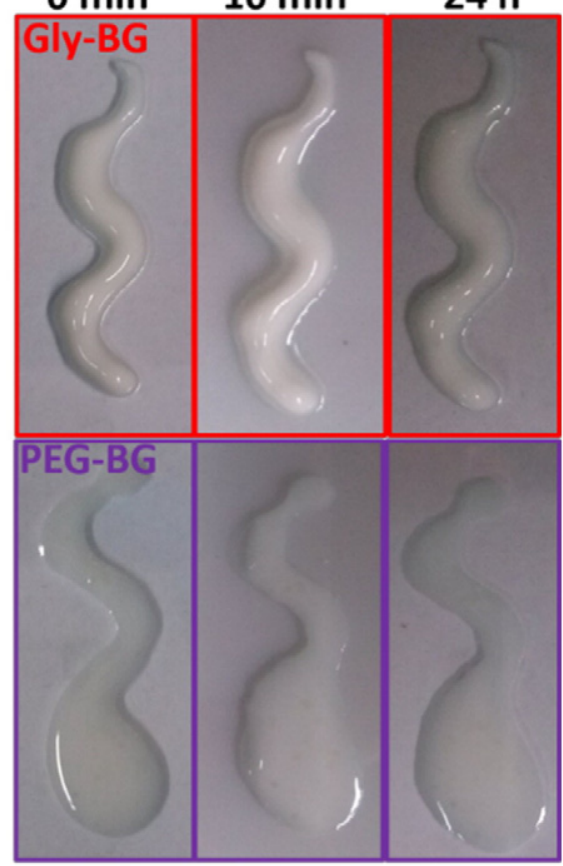

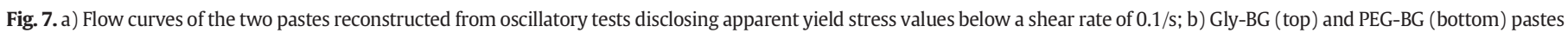
extruded from a $1 \mathrm{~mL}$ syringe through a tip diameter of $0.03 \mathrm{~mm}$ after different times ( $0 \mathrm{~min}, 10 \mathrm{~min}$, and $24 \mathrm{~h}$ ). 
conditions and levels off more easily. Considering the apparent increase in network connectivity of BG promoted by the covalent surface bonding of glycerol (is likely to decrease the biomineralization rate), the PEG-BG formulation appears as a worthy candidate as injectable bone filler.

\section{Acknowledgements}

The authors thank Dr. M. Graczyk-Zajac (TU Darmstadt, FB Materialund Geowissenschaften) for her kind help in FTIR characterization of composite materials. D. U. Tulyaganov acknowledges financial support from the German Academic Exchange Service (DAAD organization). Corneliu Balan acknowledge the financial support from the Romanina grants: PN-II-ID-PCE-2012-4-0245 and PN-II-PT-PCCA-2011-3.1-0052. Rasmus Linser acknowledges the DFG for financial support in terms of Emmy-Noether funding. This work was supported by the European Regional Development Fund (FEDER) under the PT2020 Partnership Agreement through the COMPETE, by the Portuguese Government through the Portuguese Foundation for Science and Technology (FCT), in the scope of the projects UID/CTM/50011/2013 (Aveiro Institute of Materials, CICECO,www.ciceco.ua.pt).

\section{References}

[1] T. Coradin, J. Allouche, M. Boissiere, J. Livage, Sol-gel biopolymer/silica nanocomposites in biotechnology, Curr. Nanosci. 2 (2006) 219-230.

[2] M.J. John, S. Thomas, Biofibres and biocomposites, Carbohydr. Polym. 71 (2008) 343-364.

[3] S.V. Dorozhkin, Biocomposites and hybrid biomaterials based on calcium orthophosphates, Biomatter 1 (2011) 3-56.

[4] J.R. Jones, Review of bioactive glass: from Hench to hybrids, Acta Biomater. 9 (2013) 4457-4486.

[5] M. Sohrabi, S. Hesaraki, A. Kazemzadeh, The influence of polymeric component of bioactive glass-based nanocomposite paste on its rheological behaviors and in vitro responses: hyaluronic acid versus sodium alginate, J. Biomed. Mater. Res. B Appl. Biomater. 102 (2014) 561-573.

[6] S. Hesaraki, M.H. Barounian, S. Farhangdoust, M. Khorami, A. Zamanian, S. Borhan, Mechanical and in vitro biological properties of hydroxyapatite bioceramics reinforced with strontium-containing nano-bioactive glass, Curr. Nanosci. 8 (2012) $612-622$.
[7] M.F. Koudehi, A.A.I. Fooladi, K. Mansoori, Z. Jamalpoor, A. Amiri, M.R. Nourani, Preparation and evaluation of novel nano-bioglass/gelatin conduit for peripheral nerve regeneration, J. Mater. Sci. Mater. Med. 25 (2014) 363-373.

[8] G.E. Vargas, L.A. Haro Durand, V. Cadena, M. Romero, R. Vera Mesones, M. Mackovic, S. Spallek, E. Spiecker, A.R. Boccaccini, A.A. Gorustovich, Effect of nano-sized bioactive glass particles on the angiogenic properties of collagen based composites, J. Mater. Sci. Mater. Med. 24 (2013) 1261-1269.

[9] J.E. Dumas, P.B. BrownBaer, E.M. Prieto, T. Guda, R.G. Hale, J.C. Wenke, S.A. Guelcher Injectable reactive biocomposites for bone healing in critical-size rabbit calvarial defects, Biomed. Mater. 7 (2012).

[10] J.M. Page, E.M. Prieto, J.E. Dumas, K.J. Zienkiewicz, J.C. Wenke, P. Brown-Baer, S.A Guelcher, Biocompatibility and chemical reaction kinetics of injectable, settable polyurethane/allograft bone biocomposites, Acta Biomater. 8 (2012) 4405-4416.

[11] J. Liu, K. Mao, Z. Liu, X. Wang, F. Cui, W. Guo, K. Mao, S. Yang, Injectable biocomposites for bone healing in rabbit femoral condyle defects, PLoS One 8 (2013).

[12] M. Sohrabi, S. Hesaraki, A. Kazemzadeh, M. Alizadeh, Development of injectable biocomposites from hyaluronic acid and bioactive glass nano-particles obtained from different sol-gel routes, Mater. Sci. Eng. C Mater. Biol. Appl. 33 (2013) 3730-3744.

[13] D.U. Tulyaganov, S. Agathopoulos, P. Valerio, A. Balamurugan, A. Saranti, M.A Karakassides, J.M.F. Ferreira, Synthesis, bioactivity and preliminary biocompatibility studies of glasses in the system $\mathrm{CaO}-\mathrm{MgO}-\mathrm{SiO}_{2}-\mathrm{Na}_{2} \mathrm{O}-\mathrm{P}_{2} \mathrm{O}_{5}-\mathrm{CaF}_{2}$, J. Mater. Sci. Mater. Med. 22 (2011) 217-227.

[14] D.U. Tulyaganov, M.E. Makhkamov, A. Urazbaev, A. Goel, J.M.F. Ferreira, Synthesis processing and characterization of a bioactive glass composition for bone regeneration, Ceram. Int. 39 (2013) 2519-2526.

[15] D.U. Tulyaganov, S. Agathopoulos, J.M. Ventura, M.A. Karakassides, O. Fabrichnaya J.M.F. Ferreira, Synthesis of glass-ceramics in the $\mathrm{CaO}-\mathrm{MgO}-\mathrm{SiO}_{2}$ system with $\mathrm{B}_{2} \mathrm{O}_{3}, \mathrm{P}_{2} \mathrm{O}_{5}, \mathrm{Na}_{2} \mathrm{O}$ and $\mathrm{CaF}_{2}$ additives, J. Eur. Ceram. Soc. 26 (2006) 1463-1471.

[16] S. Agathopoulos, D.U. Tulyaganov, J.M.G. Ventura, S. Kannan, M.A. Karakassides, J.M.F. Ferreira, Formation of hydroxyapatite onto glasses of the $\mathrm{CaO}-\mathrm{MgO}-\mathrm{SiO}_{2}$ system with $\mathrm{B}_{2} \mathrm{O}_{3}, \mathrm{Na}_{2} \mathrm{O}, \mathrm{CaF}_{2}$ and $\mathrm{P}_{2} \mathrm{O}_{5}$ additives, Biomaterials 27 (2006) 1832-1840.

[17] B. Tang, C. Wu, M. Qiu, X. Zhang, S. Zhang, PEG/SiO ${ }_{2}-\mathrm{Al}_{2} \mathrm{O}_{3}$ hybrid form-stable phase change materials with enhanced thermal conductivity, Mater. Chem. Phys. 144 (2014) 162-167.

[18] E.N. Hidawati, A.M.M. Sakinah, Treatment of glycerin pitch from biodiesel production, Int. J. Chem. Environ. Eng. (2011).

[19] P.J. Launer, Infrared absorption bands characteristic of the $\mathrm{SiCH}_{2} \mathrm{CH}_{2} \mathrm{CN}$ and $\mathrm{SiCH}_{2} \mathrm{CH}_{2} \mathrm{CH}_{2} \mathrm{CN}$ groups, Appl. Spectrosc. 22 (1968) 201-203.

[20] V. Chevelkov, K. Faelber, A. Diehl, U. Heinemann, H. Oschkinat, B. Reif, Detection of dynamic water molecules in a microcrystalline sample of the $\mathrm{SH} 3$ domain of alpha-spectrin by MAS solid-state NMR, J. Biomol. NMR 31 (2005) 295-310.

[21] S.M. Olhero, J.M.F. Ferreira, Particle segregation phenomena occurring during the slip casting process, Ceram. Int. 28 (2002) 377-386.

[22] S.M. Olhero, J.M.F. Ferreira, Influence of particle size distribution on rheology and particle packing of silica-based suspensions, Powder Technol. 139 (2004) 69-75. 